\title{
Experimental method of calculation to estimate the thickness of lubricating film in the friction unit depending on oil absorption of contacting surfaces
}

\author{
Dmitriy Terentyev ${ }^{1, *}$, Nikolay Ogarkov ${ }^{1}$, and Sergey Platov ${ }^{1}$ \\ ${ }^{1}$ Nosov Magnitogorsk State Technical University, Lenin Street, 38, Magnitogorsk city, Chelyabinsk \\ Region, Russian Federation, 455000
}

\begin{abstract}
The article presents the investigation of the thickness of lubricating film between contacting surfaces in heavy loaded friction units, taking into account oil absorption of rough layers. Oil absorption index depends on the kind of mechanical treatment of the surfaces and makes it possible to determine necessary characteristics of the used lubricant at the design stage of a friction unit.
\end{abstract}

\section{Introduction}

The process of interaction of contacting bodies considerably depends on the presence, size, form and supporting capacity of the lubricating film (layer) in the contact zone [1-4]. Let us examine the conditions under which lubricating film is formed taking into account the deformation of rough contacting surfaces and probable altering of properties of the lubricant.

The task is viewed as a plane, two-dimensional problem for which the relation between tensions and deformations is determined by the solution of Hertz contact problem [5], and can be realised under the following assumptions:

1) complete travels of the surface are presented as the sum of two components: the first one is the travel of the boundary of body, conditioned by the rough layer, the second one is the travel of the surface boundary without taking into account its roughness;

2) the travel of the boundary of body, conditioned by the rough layer and smooth surface are calculated based on elastic half-spaces, which are considered material continuums $[6,7]$;

3) the influence of lubricant leaks is not taken into account;

4) the pressure at the entrance edge of the lubricating film is assumed to be equal to zero, and at the exit edge - to the extreme value, i.e. $\mathrm{dP} / \mathrm{dx}=0$;

5) the lubricant is incompressible;

6) body forces, acting in the laminar flow of Newtonian liquid, are excluded;

7) modulus of elasticity of the rough layer is assumed to be proportional to the relative amount of material in the rough layer of the contacting body.

\footnotetext{
* Corresponding author: ktnterentyev@mail.ru
} 


\section{Methodology}

Under the above-mentioned assumptions the problem is reduced to the solution of Reynolds equation, the equation of dependence of the lubricant viscosity on the pressure and the equation of the thickness of lubricating film, in current coordinates on the surface.

The thickness of lubricating layer, taking into account the component, introduced by the rough layers of contacting surfaces, is calculated according to the dependence:

$$
h_{0}=h(x)\left(1+m^{\prime}+m^{\prime \prime}\right)
$$

where $m^{\prime}$ и $m^{\prime \prime}$ - oil absorption of contacting rough layers;

$\mathrm{h}(\mathrm{x})$ - the current value of the thickness of lubricating layer, conditioned by smooth surface.

The relative volume of cavities between protuberances of microrelief of the surface layer, characterizing parameter $m$ is determined by the correlation:

$$
m=\left(\frac{1}{b}\right)^{1 /(v-1)}+\frac{1}{v+1}\left[1-2\left(\frac{1}{b}\right)^{1 /(v-1)}\right]
$$

where $\mathrm{b}$ and $v$-parameters of the supporting curve of the rough layer.

Surface profilogram measurement taken after grinding and polishing resulted in the following parameter values $R_{\max }, b, v$ and $m$ (table). To provide a more concise data presentation for each type of treatment maximum parameter values for microgeometry of the rough layer are shown in the numerator, and minimum parameter values - in the denominator.

Table 1. Parameter values for microgeometry and oil absorption of the rough layer in a drawing die.

\begin{tabular}{|c|c|c|c|c|}
\hline $\begin{array}{c}\text { Type of } \\
\text { treatment }\end{array}$ & $\begin{array}{c}R_{\max }, \\
\mathrm{mcm}\end{array}$ & $b$, & $v$ & $m$ \\
\hline Grinding & $2,4 / 1,6$ & $1,3 / 1,8$ & $1,9 / 1,7$ & $0,577 / 0,481$ \\
& $1,2 / 1,0$ & $2,0 / 2,4$ & $1,5 / 1,5$ & $0,45 / 0,434$ \\
\hline Polishing & $2,4 / 1,9$ & $2,5 / 2,9$ & $1,6 / 1,6$ & $0,434 / 0,423$ \\
& $1,2 / 1,1$ & $3,5 / 3,7$ & $1,5 / 1,5$ & $0,416 / 0,414$ \\
\hline
\end{tabular}

While using the solution of Hertz contact problem, geometry of undeformed bodies can be substituted by the contact of an elastic half-space with an equivalent geometric figure. In this case a mandatory requirement is to preserve the same clearance in the direction of the principal normal of the contact and surface curvature in the area of the modelled field as in a real contact.

In this model equivalent moduli of elasticity of rough layers $\left(E_{1}^{\prime}\right)$ and smooth half-plane $\left(E_{2}^{\prime}\right)$ are determined by the following formulae

$$
\begin{aligned}
& E_{1}^{\prime}=\frac{2 E_{1} E_{2}\left(1-m^{\prime}\right)\left(1-m^{\prime \prime}\right)}{E_{1}\left(1-m^{\prime}\right)\left(1-\mu_{2}^{2}\right)+E_{2}\left(1-m^{\prime \prime}\right)\left(1-\mu_{1}^{2}\right)} \\
& E_{2}^{\prime}=\frac{2 E_{1} E_{2}}{E_{1}\left(1-\mu_{2}^{2}\right)+E_{2}\left(1-\mu_{1}^{2}\right)}
\end{aligned}
$$

where $E_{1,2}$ - moduli of elasticity of the contacting bodies,

$\mu_{1}$ and $\mu_{2}$ - Poisson's ratio of the materials of the contacting bodies.

The resultant equivalent modulus of elasticity $E_{\ni}$, which determines the sum of elastic deformations of contacting surfaces, taking into account their rough layers, is: 


$$
E_{\ni}=\frac{2 E_{1}^{\prime} E_{2}^{\prime}}{E_{1}^{\prime}+E_{2}^{\prime}}
$$

One of the assumptions in this problem is the equal deformation of the cylinder both in case of a dry contact and in case of introduction of a lubricant in the contact zone (Fig. 1).

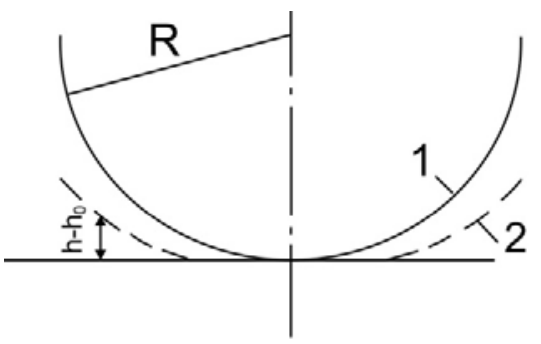

a)

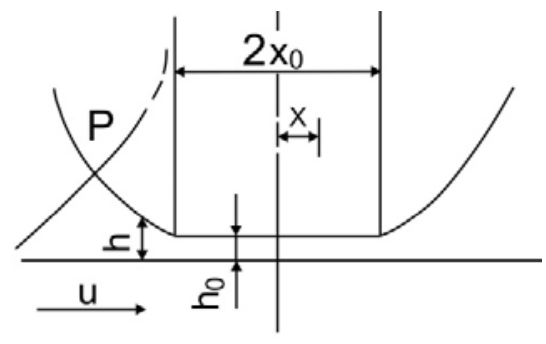

b)

Fig. 1. Contact geometry. a - surfaces without lubricant; $b$ - surfaces with lubricant; 1 - an undeformed cylinder; 2 - a deformed cylinder.

According to Hertz theory half of the contact width of a deformed cylinder is determined by the dependence:

$$
x_{ \pm 1}=2 \sqrt{2 W R / \pi \mathrm{E}_{\ni}}
$$

where $\mathrm{R}$ - the equivalent radius of curvature, determined by the correlation $1 / \mathrm{R}=1 / \mathrm{R}_{1}+1 / \mathrm{R}_{2}$.

Under the conditions of the slight temperature change and dependence of the viscosity of the lubricant $\eta$ on pressure $\mathrm{P}$ as in $\eta=\eta_{0} e^{\alpha P}$ and taking into account Reynolds equation and the pressure at the border of Hertz joint $\left(x_{ \pm 1}\right)$, the dependence for calculating the thickness of lubricating film for contacting bodies with rough surfaces was deduced:

$$
h_{0}=0,888 \cdot\left(1+m^{\prime}+m^{\prime \prime}\right) \cdot(\alpha \cdot \eta \cdot v)^{0,727} \cdot R^{0,364} \cdot\left(\frac{E_{9}}{W}\right)^{0,111}
$$

where $\eta_{0}$ - viscosity at atmospheric pressure;

$\alpha$ - pressure coefficient of viscosity;

$v$ - hydromechanical velocity, which creates hydromechanical pressure between contacting surfaces, and is determined by the velocity with which the surfaces move.

Then analytical calculations of the thickness of lubricating film in rolling bearings, used in friction units of machines and aggregates in metallurgical production, were made. As an example, in the figures below one can see dependences of the thickness of lubricating film, calculated according to well-known I.D. Ratner dependence (without taking into account oil absorption of contacting surfaces) and dependence (7), suggested by the authors. 


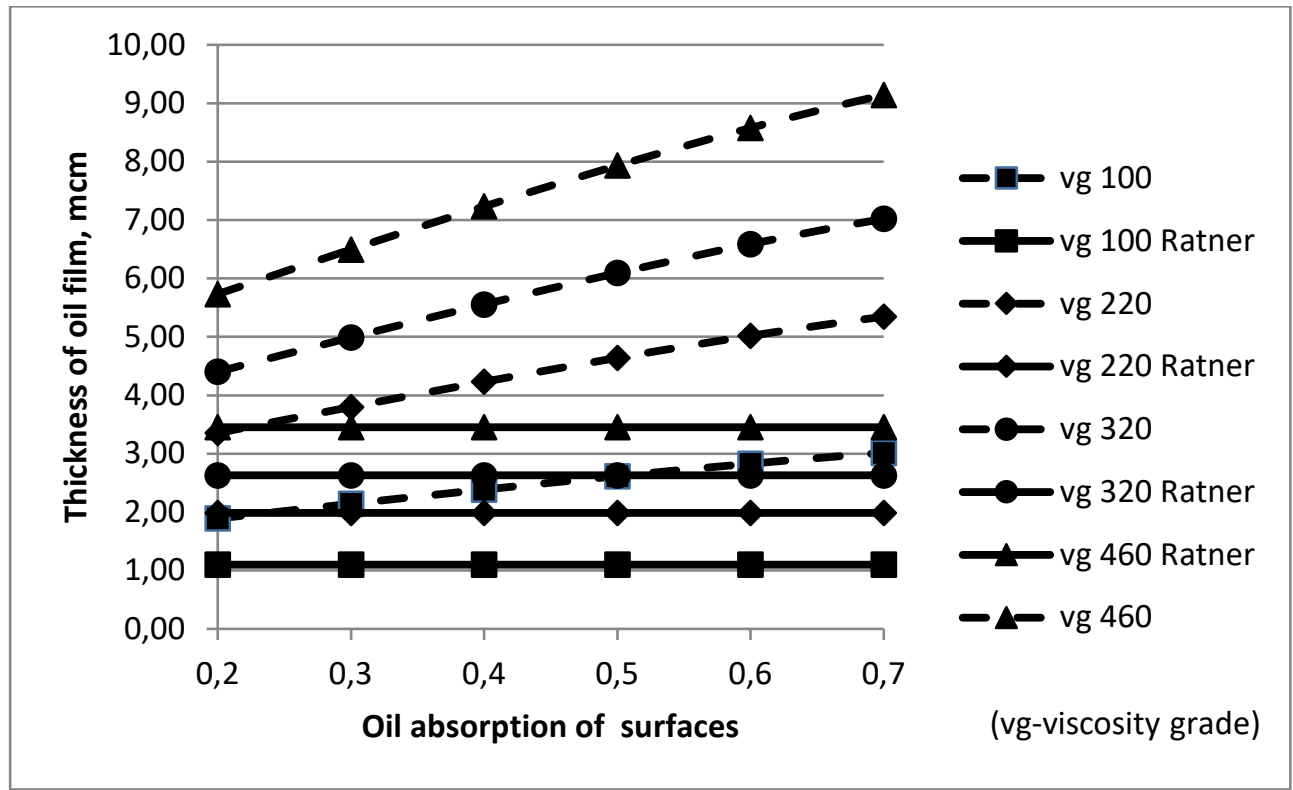

Fig. 2. Dependences of the thickness of lubricating film on oil absorption of contacting surfaces for lubricants with different viscosity grade

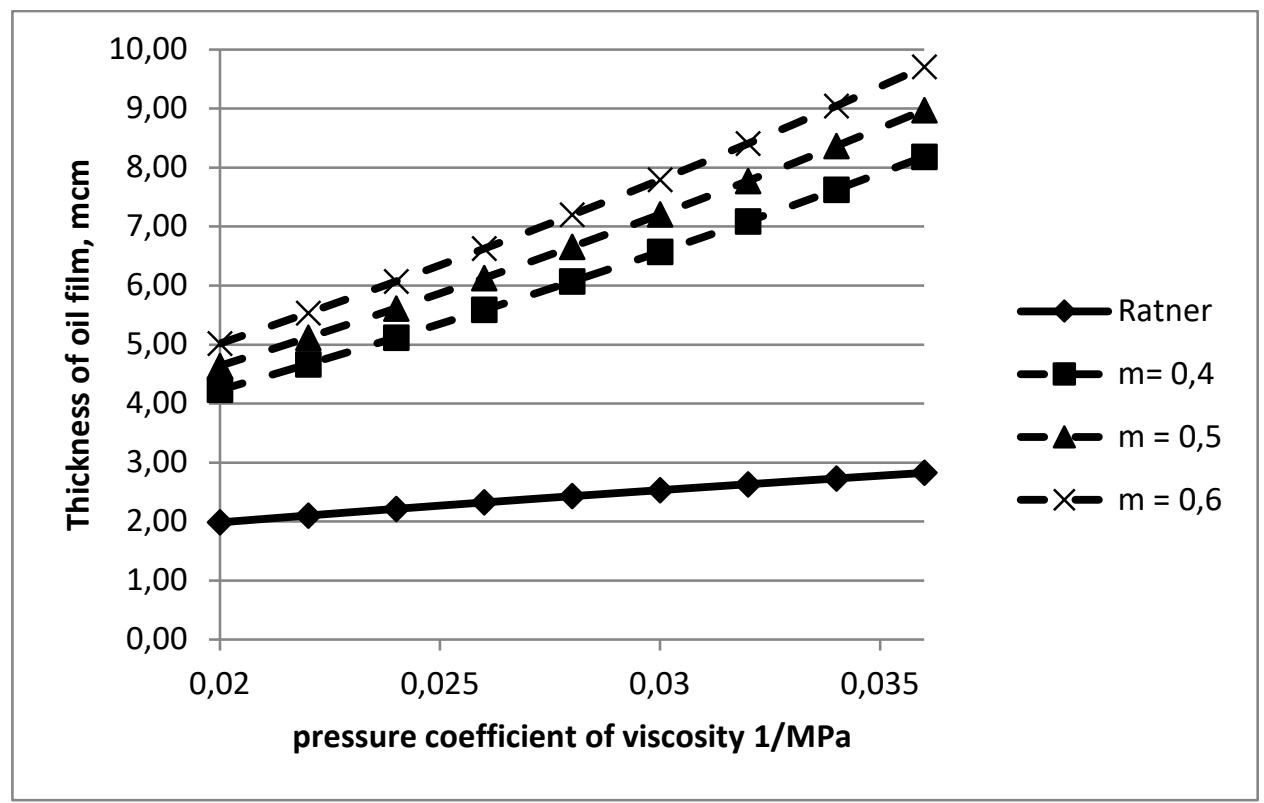

Fig. 3. Dependences of the thickness of lubricating film on pressure coefficient of viscosity for different oil absorption of contacting surfaces 


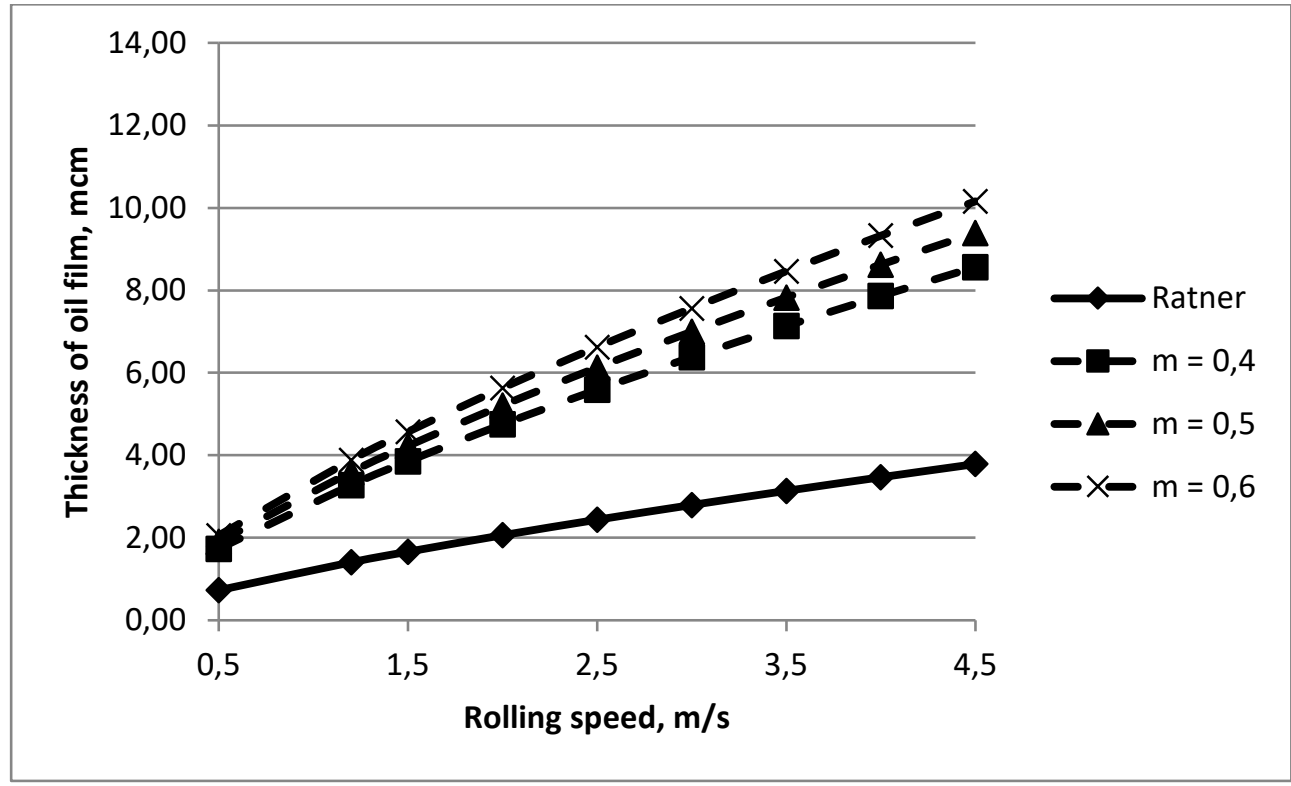

Fig. 4. Dependences of the thickness of lubricating film on rolling velocity for different oil absorption of contacting surfaces

\section{Summary}

In order to check adequacy of the deduced dependence of the thickness of lubricating film experimental investigation was carried out on the friction machine. In the course of experiments an analytic method was used to calculate the thickness of lubricating film in the friction pair roller-roller. Three pairs of rollers were examined: after turning, grinding and polishing. It made it possible to model friction surfaces with different roughness and, therefore, oil absorption. Experiments were conducted with different rotational velocity of rollers and specific load. The obtained results demonstrate convergence of theoretical and experimental data at the level of $85-87 \%$.

Data analysis proves that the dependence, deduced by the author, makes it possible to calculate the thickness of lubricating film in friction units when surfaces contact each other with relative displacement, taking into account oil absorption of rough layers.

\section{References}

1. A.V. Chichinadze, Je. M. Berliner, Je. D. Braun, Friction, tear and wear and lubrication (tribology and tribo-engineering), Moscow, Mashinostroenie, 576 p. (2003)

2. D.V. Terentyev, S.I. Platov, Ju.V. Zhirkin, Modelling of frictional operation conditions of bearing units in slab continuous casting machines to choose rational lubrication modes, Chernye metally, No. 4 (976), pp. 11-14 (2013)

3. S.I. Platov, D.V. Terentyev, Ju.V. Zhirkin, Research and development of regimes for lubrication bearing units in working rolls at hot rolling mill 2000, Vestnik Magnitogorskogo gosudarstvennogo tehnicheskogo universiteta im. G.I. Nosova [Vestnik Nosov of Magnitogorsk State Technical University], No 2, pp. 98-100 (2012) 
4. D.V. Terentyev, S.I. Platov, Ju.V. Zhirkin, Development of rational modes of lubrication of bearing units in slab continuous casting machines, Nauchnotehnicheskie vedomosti Sankt-Peterburgskogo gosudarstvennogo politehnicheskogo universiteta [Scientific and technical journal of the St. Petersburg State Polytechnic University], No 1 (190), pp. 164-168 (2014)

5. S.P. Demidov, Theory of elasticity, Moscow, Vysshaja shkola, No 1 (190), pp. 164-168 (1979)

6. E.S. Shemetova, N.N. Ogarkov, Estimation of the length of the contact of curvilinear drawing die by deformed material, taking into account its elastic deformation, Vestnik Magnitogorskogo gosudarstvennogo tehnicheskogo universiteta im. G.I. Nosova [Vestnik Nosov of Magnitogorsk State Technical University], No 2. pp. 38-40 (2010)

7. N.N. Ogarkov, S.I. Platov, E.S. Shemetova, D.V. Terentiev, V.A. Nekit, M.N. Samodurova, Oil absorption capacity of the contact surfaces in metal-forming processes, Metallurgist. v. 61, No 1-2, pp. 58-62 (2017)

8. D.S. Kodnir, E.P. Zhil'nikov, Ju.I. Bajborodov, Elastohydrodynamic calculations of machine components, Moscow, Mashinostroenie, 160 p. (1988) 